\title{
Research on Innovative Management of Community Bookstore
}

\begin{abstract}
ZHANG Lin
Shandong Technology and Business University, Yantai, 264005, China

Email: zhanglin19981998@126.com

ABSTRACT

In the past few years, community bookstores have re-emerged in many places in China. Based on the analysis of the three challenges that community bookstores confront, such as limited market size and high operating costs, competition from online bookstores, and consumers' electronic and fragmented reading methods. The article explored the innovation in the management of community bookstores from three perspectives: the positioning of business, the using of operating resources and the choice and implementation of business strategies.
\end{abstract}

Keywords: community bookstore, innovative management, positioning, business strategy

\section{INTRODUCTION}

With the economic development and advancement of urbanization, new type of communities characterized by considerable scale, professional planning, complete supporting facilities and beautiful green environment have emerged, which have greatly improved people' $\mathrm{s}$ living environment and conditions. People's material living standards have been greatly improved, so spiritual and cultural life, such as leisure, entertainment and social contact, has begun to attract people's attention. Accordingly, in the past few years, as an important participant and promoter of nationwide reading activities and the construction of scholarly society, community bookstores have re-emerged in Beijing, Sichuan, Jiangsu, Henan and many other places in China, and play an important role in the construction of community culture and spiritual civilization. However, for community bookstores, their successful operation is still faced with many challenges. Operators need to innovate in positioning, resource utilization, and business strategy to meet the reading and cultural consumption needs of community residents effectively.

\section{CHALLENGES FACED BY COMMUNITY BOOKSTORES}

Due to its own characteristics and changes in the external environment, community bookstores are faced with challenges such as limited market size, high operating costs, competition from online book operators and consumer's fragmented and electronic reading habits.

\subsection{Challenges of limited market size and high operating costs}

Traditionally, large bookstores and specialty bookstores are located in urban commercial centers, cultural centers or characteristic open blocks where people gather. Their consumption groups are consumers from the whole city or a certain area of the city. For the wide radiation range of the business district, both the scale of the market and the bookstore are large. The bookstore provides a wide variety of books which can meet the diverse needs of readers and can obtain a certain scale economy effect. However, due to the location of community bookstores, their target consumers are mainly residents in the community, and the size of the market is limited by the size of the community. In China, even the new large-scale community has a population size of only 30,000 to 50,000 . The population of a large number of small and medium-sized communities is far less than this number, only a few thousand people. In addition, many communities are gated community. Except for community residents, there are very few outsiders. Therefore, the limited market size determines that the size of community bookstores is generally small and the sales volume of books is limited. It is difficult to achieve economies of scale effect, resulting in community bookstores facing the situation of high operating costs and successive losses. For example, although the Beijing community bookstore Edin Island has been in business 
for many years, the operators have not been paid wages for many years. Even so, the operating situation is not optimistic and it has been at a loss for a long time. Its operating costs are mainly reflected in employee salaries, rent of property and books, which account for about $40 \%$, $40 \%$ and $20 \%$ respectively. ${ }^{[1]}$

\subsection{Challenge of Online Bookstore Competition}

Because of the virtual nature of its space, the online bookstore has broken through the limitation of the traditional physical bookstore's operating area, and the types of books they operate are greatly enriched. For example, Amazon, the leader of online bookstores, has more than 7 million kinds of books, Dangdang has more than 800,000 kinds of books and audio-visual goods in stock, they can fully meet the consumers' diversified needs of books. Moreover, the business scope of these online bookstores is not limited to books for a long time, and the types of business commodities they operate are becoming more and more abundant. They have changed from simple book operators to comprehensive ecommerce based on book management, and their effects of economies of scope are gradually promoted. Moreover, the network has also broken through the limitation of operating region and operating time, and its buyers are all over the country and even the world. As long as consumers can access the Internet, they can buy books online anytime and anywhere, which makes online bookstores have huge economies of scale and win lowprice competitive advantage. In addition, the book review function of online bookstores also provides a useful reference for consumers' book selection, and its delivery efficiency is constantly improving. All of these have made online bookstores favored by a considerable number of consumers. According to the "2019 China Book Retail Market Report" released by Beijing Openbookscan Information Technology Co., Ltd., in 2019, the national book retail market grew by $14.4 \%$ year-on-year, the size of the physical bookstore market increased negatively year-on-year, and online stores grew by $24.9 \%$ year-on-year. The challenges and impacts of online bookstores on physical bookstores including community bookstores cannot be ignored.

\subsection{The challenge of consumer's electronic and fragmented reading methods}

With the advent of the mobile Internet era and the rise of digital reading, people's reading media, reading content and reading time are all changing. In addition to traditional paper books, people also read through mobile phones, e-readers, CDs, Pads, computers, etc., especially mobile phones, which have become important reading tools for consumers. WeChat, QQ, and web pages have become the main targets of their online reading. The time spent on mobile phones to surf the Internet has been increasing year by year. According to the latest report of the 18th National Reading Survey released by the China Press and Publication Research Institute, in 2020, the contact rate of adult citizens in my country with digital reading methods (online reading, mobile phone reading, e-reader reading, Pad reading, etc.) is $79.4 \%$, an increase of 0.1 percentage point from 2019. Among them, the mobile phone reading contact rate of adult citizens reached $76.7 \%$, which was 0.5 percentage points higher than that in 2019. The average daily mobile phone contact time of adult citizens was 100.75 minutes, an increase of 0.34 minutes compared with 2019. The mobile phone reading contact rate of adult citizens in China has increased year by year. There is a tendency of fragmentation, entertainment, and popularization in consumers' reading habits, which affects people's choice of paper books that are characterized by a systematic presentation of content and require more in-depth thinking, and also affects the operation of community bookstores.

The various challenges mentioned above require continuous innovation in many aspects of community bookstores' management to solve the problems caused by the above challenges, helping community residents reshape their reading and cultural preferences, and jointly build community culture, so that the community will not only become the home of community residents' material lives, but also become the paradise for spiritual life.

\section{INNOVATIVE BUSINESS MANAGEMENT PATH OF COMMUNITY BOOKSTORES}

Community bookstores can explore innovative paths and methods from the aspects of business positioning, utilization of business resources and selection and implementation of business strategies.

\subsection{Positioning innovation, changing from a book seller to a provider of cultural space}

Traditionally, physical bookstores are mainly positioned as sellers of books, and through the sale of books and related products, they meet the needs of consumers for knowledge acquisition, sentiment cultivation, and vision expansion. These needs are only part of the consumer's cultural needs. With the development of the times, consumers have put forward higher requirements for this demand, and many related needs have arisen. For example, many consumers not only want to obtain knowledge through books, but also hope to obtain reading guidance in related aspects through lectures and other methods. They also hope to communicate and discuss the content of books and a certain field of knowledge with relevant people to deepen their understanding of related knowledge. Sometimes they want to put the learned knowledge into practice on 
site and show relevant results. At the same time, in order to cope with the stressful work and life and save time, they also hope that while acquiring knowledge, they can also meet other needs, such as leisure, entertainment, making friends or life services. Therefore, community bookstores should carry out positioning innovations in accordance with the changes of the times, and transform from the traditional book sellers to the providers of cultural spaces. The main business is no longer just book sales, but a collection of cultural services and related life services that integrate book sales, cultural activity organization, and cultural achievement display.

Many of the community bookstores that have emerged in China in recent years have undergone changes in their positioning in this regard. For example, the community bookstore "Oracle Bones Script · Happy Reading Space", which is reconstructed by the public library in Xicheng District of Beijing, not only retains the original public library's book borrowing function and book selling, but also adds coffee meal, cultural and creative products, membership services, public welfare activities and other services. It forms six series of brand activities with "community" as the core, including community reading club, community poetry club, community story club, community life club, community film club and community open classes. It organizes various reading activities for community residents every weekend. At the same time, a series of targeted activities are held for special seasons and special groups. For example, during the summer vacation, Oracle Bones Script Happy Reading Space planed and launched "close library series activities" for students, such as "when the writer meets the bookstore", "when the good voice meets the bookstore", "when the student meets the bookstore". These activities are characterized by writer sharing, broadcast artist training and children's practical experience, attracting more cultural resources and charity individuals walk into the community, walk into the community bookstore and carry out reading. The community bookstore has become a back garden of the spiritual and cultural activities for community residents. ${ }^{[2]}$ In addition, Oracle Bones Script- Happy Reading Space also operates a variety of cultural and creative products such as mobile phone shells, handwritten heart scripts, literary postcards, bookmarks, and immortal flowers, meeting the different cultural consumption needs of community residents. ${ }^{[3]}$

\subsection{Innovative ways of utilization of operating resources by multi-party alliances and cooperative operations}

For small-scale community bookstores, especially independent private community bookstores, the available resource conditions are very limited. How to obtain capital, business premises, manpower, material resources and other related operating resources in an economical way and reduce operating costs to meet the needs of community residents have become the key to its success. The community bookstore can make full use of the existing resources of other organizations and institutions in the society, and adopt a multi-party alliance and mutually beneficial cooperation mode of operation to jointly meet the cultural needs of community residents.

In terms of funds, community bookstores can make full use of the guiding ideology of the National Reading Development Plan during the "Thirteenth Five-Year" Period and the policy of strong support for community bookstores to cooperate with the government departments in charge to obtain financial and resource support. Then they can jointly carry out public welfare cultural activities and build a scholarly society together. Crowdfunding can also be used to mobilize readers or community residents to provide the funds needed for business operations. In the business place, community bookstores can cooperate with community property companies and real estate developers in service projects. By helping property management companies through undertaking some community construction functions, integrating cultural characteristics into the brand image and publicity of real estate companies, they can make low-cost or free use of vacant houses of property management companies or real estate developers. In the operating management system and brand image, community bookstores can cooperate with large physical bookstores by joining the large-scale bookstore chain management system as its unified standardized terminal. With brand reputation and mature management system of the large-scale bookstore, community bookstores not only can gain consumer's recognition, but also can take the advantages of centralized procurement to reduce procurement costs. In terms of specific service items and business strategies, different cooperative institutions can be selected according to the differences in business items and business strategies. For example, a community bookstore can cooperate with libraries to provide community residents with book borrowing services in the community. In the purchase and collection of books, community bookstores can cooperate with online bookstores as the distribution and service terminal of online bookstores. The collaborative management of online and offline will facilitate online ordering, retrieval and return services of books. Community bookstores can cooperate with cultural institutions and book clubs to provide community residents with a variety of cultural activities by using the human resources, event organization experience, and online and offline communication and publicity channels of these organizations.

Wenxuan Reading Books which is community bookstore in Chengdu adopts the mode of multi-party cooperation among government departments, community subdistrict office, Xinhua Wenxuan, libraries and other social service institutions, and has successfully opened 
several community chain bookstores. Under this model, Chengdu Municipal Bureau of Culture, Broadcasting and News which is the relevant government department is the leader of the community bookstore project and responsible for the coordination of property resources. The district and county governments and communities subdistrict office are responsible for the construction and promotion of the project and provide properties for free; Xinhua Wenxuan takes advantage of its own abundant resources such as books, data, logistics, planning, and manpower to be responsible for fund, construction and operation management, including bookstore decoration, book update, professional management, and improvement of the reading environment. ${ }^{[4]}$ The library repurchases the new books which have reached a certain amount of free borrowing. Telecom operators, express delivery enterprises and financial institutions cooperate with Wenxuan Bookstore to provide a variety of convenience services including broadband handling, express delivery and convenience payment in the bookstore. ${ }^{[5]}$ In the reading activities, the Wenxuan Reading Books community bookstore carried out various non-profit cultural activities by introducing external resources, such as plant cultivation, health lectures, education lectures, quality education, children's English, painting. On the other hand, it also promoted the "Volunteer Program" among readers to mobilize volunteers to participate in reading activities. Volunteers who provide reading services and organize activities will get points. If the points reach a certain number, they can take priority to participate in activities and redeem goods. These designs attracted many residents in the community with expertise to actively participate in the "volunteer program." [4]

\subsection{Innovation in business strategy by focus on research, precision marketing, and flexible operation}

In order to make full use of various resources to effectively meet the limited but diversified cultural needs of the community, the community bookstore should pay attention to market research during the operation process and conduct in-depth research on community residents by issuing questionnaires, consumer interviews, and discussions. Based on the understanding the cultural needs of community residents, the innovation of business strategies such as store space planning and design, book selection and display, design and organization of reading and cultural activities, pricing and promotion, and communication and communication with readers are carried out to implement precision marketing and flexible management.

In the planning and design of the store space, the community bookstore needs to reasonably divide the space (by its) function according to the bookstore's positioning and operating service content, such as the division of commodity display area, online reading area, offline reading area, activity area. On this basis and through creative design, the cultural atmosphere of the bookstore is created, which brings attractive and beautiful experience to the residents who enter the store. For example, Oracle Bones Script - Happy Reading Space divides the bookstore into book display area, adult reading area, parent-child reading area, coffee area and activity area. Different areas adopt different designs and decoration styles. The adult reading area uses a retro style to create a quiet atmosphere; the parent-child reading area uses colourful patterns and shapes to create a lot of childishness. The bookstore also adheres to the concept of green, thrift and environmental protection. Various green plants are cleverly arranged in the sky above the adult reading area, on the shelves, decorations, and corners of the store, making the entire bookstore full of vitality.

In the selection and display of books, community bookstore should select books for readers according to the characteristics of age, occupation and reading preference of community residents. Online and offline book selection channels should be opened for consumers to allow consumers to participate in the purchase of books. Community bookstore should also break the routine and classify and display the books in an attractive way. For example, books can be used for display styling to shape the atmosphere of the bookstore and bring new ideas and appeal to the store. Related display in retail can be used by community bookstore to connect the books and cultural and creative products that community residents may have related needs. Books can also be displayed by corresponding themes or topics along with the holiday changes. For example, the aforementioned community bookstore "Oracle Bones Script · Happy Reading Space" creatively divides books into six series including "fauvism", "impressionism", "idolism", "strength", "suspense", and "movie", respectively representing the workplace and economic management books, foreign translated books, books written by celebrities or hosts, books of literary masters, books of reasoning novels and books of film art, which makes the classification of books lively and interesting, reflecting the literary atmosphere of the bookstore. ${ }^{[2]}$

In the design and selection of reading and cultural activities, community bookstore should organize them according to the needs of community residents. Regular reading activities can be organized several times per week or month. Temporary activities with special theme can also be organized according to the special needs of residents. In the organization of activities, the strength of community residents can be fully utilized. Depending on the specific circumstances, activities may be organized by enthusiastic people in the community, hosted or lectured by residents with expertise, or attract the social resources of community residents to participate in the activity. By designing a certain incentive system, 
community bookstore can mobilize the enthusiasm of community residents, attract them to participate in community activities and make contribution to the construction of community cultural activities. In addition, community bookstore can also cooperate with influential book clubs in the society in the long term to provide diverse reading activities for the community by making full use of the resources these book clubs have.

In terms of pricing and promotion, in addition to traditional promotional activities such as discounts and gifts, innovative promotional activities can be organized according to the characteristics of community residents. Community bookstore can hold knowledge contests, article sharing and presentation, and other culturalrelated creative activities to attract residents' attention to community culture and community bookstores. For example, Hangchen Bookstore in Hangzhou Vanke Community launched the "Book Bank" activities, in which community residents can replace a new book with old books other than magazines, newspapers and textbooks, and obtain book borrowing cards and consumer funds. These activities have been recognized and praised by users.

In the communication with consumers, community bookstores can set up multiple online and offline communication and publicity channels to communicate with community residents in all directions. For online, community bookstores can use the WeChat official account to timely deliver the information of books, services, activities and other related business activities of the bookstore to the community residents. At the same time, the official account is also run as the query system of member information if the bookstore operates based on membership system. Members can use the official account to query consumption information, book borrowing information, points information and other information. The official account can also be used as a display platform for cultural works to display residents' articles, paintings and other cultural works. A resident WeChat group can be set up as an interactive platform to initiate discussions on books, reading and cultural activities within the group, and encourage residents to put forward suggestions and opinions on the service of bookstores by the group. Community bookstore can also open micro-blog to record and share bookstore's operation and growth process, share cultural knowledge, information and insights. For offline, the bookstore can also choose people with communication expertise among the staff or residents to handle the publicity and communication with the community residents, and set up a special guestbook or message display board for residents to leave messages, graffiti, and encourage residents to communicate in a creative way. Through the collaborative communication of online and offline, on the one hand, consumers' opinions and suggestions are collected to improve the service content, mode and level of bookstores. On the other hand, the management information of bookstores is transmitted to community residents in time to achieve the purpose of building community culture and improving spiritual life together.

\section{CONCLUSION}

The article analyses three major challenges the community bookstore currently faces in its operations including limited market size and high operating costs, competition from online bookstores, and consumers' electronic and fragmented reading methods. It provides innovative ideas and strategies for community bookstores to deal with challenges from multiple dimensions. In terms of business positioning, it can transform from a book seller to a provider of cultural space; in the use of operating resources, it can seek multi-party alliances and cooperative operations; in terms of business strategy, based on in-depth research and understanding the cultural needs of community residents, the innovation of business strategies such as store space planning and design, book selection and display, design and organization of reading and cultural activities, pricing and promotion, and communication and exchanges with readers can be carried out to implement precision marketing and flexible management.

\section{REFERENCES}

[1] Chen Jie, Li Bohan. The Interpretation of Beijing Community Bookstore Samples [N].Beijing Business News Daily. Cultural and Creative Industries Weekly 2014-05-23.

[2] Liu Yao. "Oracle Bones · Happy Reading Space ": "Spiritual Back Garden "in the Community [N].China Press Publication Radio Film and Television Journal, 2016-09-26.

[3] Wang Shaobo. A Community bookstore customizing reading activities for residents $[\mathrm{N}]$.China Publishing \& Media Journal, 2017-02-27 ( 010 ).

[4] Zuo Zhihong.Wen Xuan Reading Book: to create a community bookstore of "Chengdu model" [N]. China Press Publication Radio Film and Television Journal, 2016-11-14.

[5] Wen Feng. Community Bookstores Race to Upgrade the 3.0 Model. China Publishing Media Network, http://www.cbbr.com.cn/article/105126.html, 201607-08.E.M. Clarke, E.A. Emerson, Design and synthesis of synchronization skeletons using branching time temporal logic, in: D. Kozen (Eds.), Workshop on Logics of Programs, Lecture Notes in Computer Science, vol. 131, Springer, Berlin, Heidelberg, 1981, pp. 52-71. DOI: https://doi.org/10.1007/BFb002577 